\title{
Reproductive Outcomes of Patients with Septate Uterus After Hysteroscopic Septoplasty: A Retrospective Study in Chinese Women
}

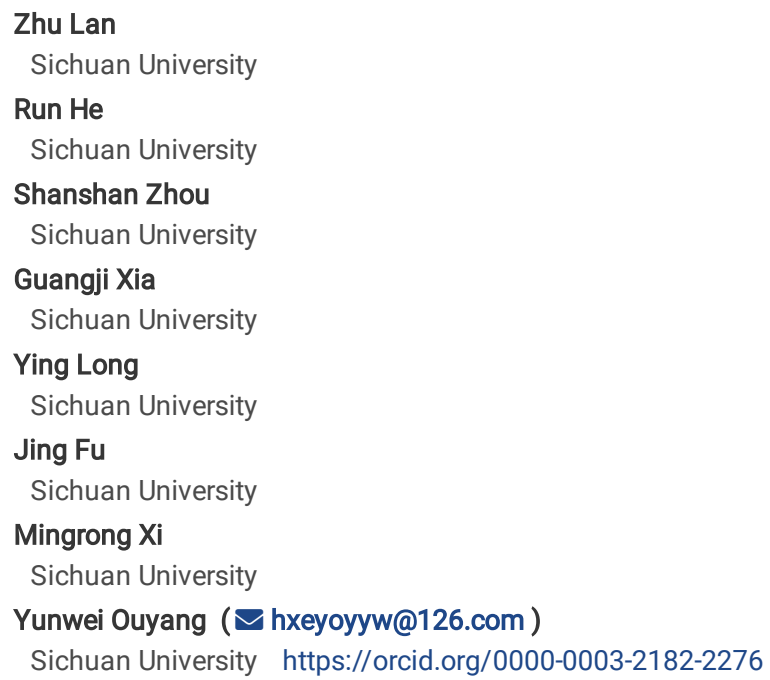




\section{Abstract \\ Objective}

Septate uterus is the most common structural uterine anomaly, which is related to the adverse pregnancy outcomes in women of childbearing age. At present, there are still controversies about the surgical treatment of septate uterus both nationally and internationally. This article provides a retrospective review of hysteroscopic uterine septum resection performed in our hospital during recent years, focusing on the patients with recurrent miscarriage and infertility.

\section{Methods}

This is a single-center retrospective cohort study. Cases of women who underwent hysteroscopic septum resection at West China Second Hospital of Sichuan University from January 2014 to December 2019, retrieved through the medical record system, were divided into three groups: Group A was the recurrent miscarriage group, Group B had a history of pregnancy with spontaneous abortion once at most; Group C was the primary infertility group. Each patient was followed up by telephone about further pregnancy, miscarriage, and live birth for at least 1 year.

\section{Results}

A total of 176 surgical patients were included in this study. The overall pregnancy rate increased from $65.91-77.27 \%$ after surgery, the live birth rate increased from $7.95-67.61 \%$, and the spontaneous abortion rate decreased from $46.59-17.05 \%$. The postoperative pregnancy and spontaneous abortion rates in Group A were not significantly different from the other two groups, but the live birth rates were still significantly lower. For patients with complete uterine septum, the preoperative pregnancy rate was $54.84 \%$, which was significantly lower than patients with partial uterine septum (71.93\%). After hysteroscopic metroplasty, the pregnancy rate increased to $85.48 \%$ in patients with complete uterine septum, and $72.81 \%$ in the partial uterine septum group, but no statistical difference was observed.

\section{Conclusions}

After uterine septum resection, the overall pregnancy rate and live birth rate increased, and the spontaneous abortion rate decreased. However, the postoperative live birth rate and term delivery rate of RSA patients were significantly lower than other two groups. Patients with complete uterine septum may benefit more from surgery. The surgical indications should be carefully and strictly evaluated.

\section{Introduction}

Septate uterus is the most common congenital uterine anomaly, accounting for more than half of all cases ${ }^{[1]}$. It is caused by complete or partial failure of resorption after the fusion of the two Müllerian ducts during embryonic development ${ }^{[2]}$, and is mainly related to poor pregnancy outcome in women of childbearing age, such as recurrent spontaneous abortion (RSA), premature birth, fetal malpresentation, stillbirth, fetal malformation, fetal growth restriction, placental abruption, etc. ${ }^{[3]}$, the rate of full-term delivery is only $40 \%[4,5]$

The exact mechanism of adverse reproductive outcomes caused by septate uterine is still unknown. There is a general consensus that uterine mediastinum may influence the embryos implantation because the absence of local endometrial vascular endothelial growth factor (VEGF) receptor results in maldevelopment of placenta ${ }^{[6,7]}$. Some scholars believe that the muscle fibers of uterine mediastinum has lower sensitive to steroid hormones ${ }^{[8]}$, and the uncoordinated contraction of muscle fibers can also lead to miscarriage ${ }^{[9]}$.

A number of retrospective studies have shown ${ }^{[10-12]}$ that removal of the uterine septum and restoration of the normal uterine architecture can help reduce the rate of spontaneous miscarriage and increase the rate of live births, especially for women with a history of adverse pregnancy outcomes. However, there is a lack of high-quality evidence-based medical evidence for these benefits. In recent years, several newly published multi-center clinical studies have brought this traditional belief into question ${ }^{[13,14]}$, Hence, the controversy about the "overtreatment" of the septate uterus is endless ${ }^{[15]}$. In China, rich experience has been accumulated in the surgical treatment of the septate uterus with the widespread application of hysteroscopic. Therefore, this study reviewed and summarized the clinical information form 176 patients who underwent this procedure at our hospital in the past recent years and their subsequent pregnancy outcomes were traced. We aimed to explore the value of hysteroscopic resections of the uterine septum, especially focusing on the patients with recurrent miscarriage and infertility.

\section{Methods}

\section{Study population}

The present study was a single-center retrospective study. Women who underwent Septum resection at West China Second Hospital of Sichuan University from 2014 to 2019 were retrieved by searching the electronic medical record system, and basic information such as age, BMl, and history of pregnancy and childbirth were collected. The preoperative diagnosis primarily based on imaging ${ }^{[3,16]}$ (ultrasound, magnetic resonance imaging, or hysterosalpingography). The exclusion criteria for the cases were: Case exclusion criteria: 1 . aged $>45$ years; 2 . Patients with pelvic abscess, pelvic tuberculosis, premature ovarian 
insufficiency, premature ovarian failure, amenorrhea. 3. Recurrent spontaneous abortion caused by factors such as immunity, endocrine, genetic abnormalities, infection, etc. 4.Women without reproductive requirements; 5. Patients who lost to follow-up.

According to the preoperative fertility status, the included cases were divided into three groups: Group A is the recurrent miscarriage group, defined as 2 or more consecutive pregnancy losses according to the American Society of Reproductive Medicine (ASRM) ${ }^{[17]}$ and the European Society of Human Reproduction and Embryology (ESHRE) ${ }^{[18]}$; Group B has a history of pregnancy but spontaneous abortions happened no more than once; Group C has no history of pregnancy, which means primary infertility. This study was granted the ethical committee approval from the hospital's medical ethics committee and all patients signed the informed consent.

\section{Surgical Technique}

Hysteroscopy is performed during the follicular phase of the menstrual cycle. The day before the operation, misoprostol or a disposable cervical dilator is used to soften the cervix. Hysteroscopy combined with laparoscopy was performed for patients with unclear diagnosis of uterine malformations, infertility, spaceoccupying lesions of the uterine adnexa and secondary dysmenorrhea ${ }^{[19]}$. The hysteroscopic metroplasty is performed under general anaesthesia and can be monitored by ultrasound imaging. According to the ESHRE/ESGE classification system ${ }^{[20]}$, the standard for complete resection of the uterine mediastinum is that the thickness of the myometrium of the uterine fundus returned to the normal range. A combination of estrogens, Foley balloon or T-shaped intrauterine device is used to prevent postoperative intrauterine adhesions. In accordance with the intraoperative and postoperative situation, hysteroscopic operations should be performed again if necessary.

\section{Follow Up And Case-control Study}

After surgery each participant was followed up by telephone to collect the information of first pregnancy, the mode of delivery, the gestational age, the number of miscarriages etc, and to determine whether the patient had received any form of assisted reproduction technology for conception. The minimum follow-up duration was 12 months for all patients.

Then a retrospective case-control study is performed to search the possible influence factors on different pregnancy outcomes of the included cases: Women with septate uterus combined with primary infertility are divided into postoperative pregnancy group and postoperative infertility group, the exposure factors evaluated were age, BMI, menstrual status, septum size, surgical method, endometriosis, endometrial polyps and postoperative adjuvant treatment.

Similarly, patients with septate uterus combined with recurrent miscarriage are divided into live birth group and non-live birth group, according to the reproductive outcome after hysteroscopic metroplasty. The exposure factors include the number of preoperative pregnancy, the number of spontaneous abortions, age, BMI, menstruation, septum size, surgical methods, endometriosis, endometrial polyps, and postoperative adjuvant treatment.

\section{Statistical analysis}

Measurement data such as age and BMI were expressed as mean \pm standard deviation (SD) and were compared using simple t-test; Mc Nemar test was applied to compare the differences in pregnancy outcomes before and after surgery; Chi-square test was used for subgroup analysis. The statistical software is SPSS version 13.0 (SPSS, Chicago, Illinois, USA), and a value with a P value less than 0.05 is considered to be statistically different.

\section{Result}

\section{Baseline characteristics}

As shown in Figure 1, a total of 176 surgical patients were included in this study, and all cases had no complications such as uterine perforation or water intoxication. Among the included cases, 42 patients had a history of recurrent miscarriage (Group A), 60 patients were diagnosed as primary infertility (Group C) before surgery, and a total of 71 patients had a history of secondary infertility. A total of 35 patients underwent secondary surgical exploration, accounting for $19.89 \%$ of the all cases. The basic characteristics of the included cases are shown in Table 1 . There were no significant differences in age, BMI, reoperation rate, live birth rate, or postoperative adjuvant treatment among the three groups. In Group A, women with complete uterine septum accounted for $21.43 \%$, while in Group C, complete uterine septum accounted for $46.67 \%$, there was a significant difference between the two groups. In the choice of surgical modalities, the numbers of hysteroscopy combined with laparoscopic exploration in the three groups were 6 (14.29\%), 36 (48.65\%), and 49 (81.67\%), respectively, with statistical differences. 
Table 1

Basic characteristics of the included patients.

\begin{tabular}{|c|c|c|c|c|c|c|c|}
\hline & Total $(n=176)$ & $\begin{array}{l}\text { Group A } \\
42(23.86 \%)\end{array}$ & $\begin{array}{l}\text { Group B } \\
74(42.05 \%)\end{array}$ & $\begin{array}{l}\text { Group C } \\
60(34.09 \%)\end{array}$ & $\begin{array}{l}\text { Group Avs.B } \\
\text { P value }\end{array}$ & $\begin{array}{l}\text { Group Avs.C } \\
\text { P value }\end{array}$ & $\begin{array}{l}\text { Group Bvs.C } \\
\text { P value }\end{array}$ \\
\hline Age (mean, SD) & $27.94 \pm 3.83$ & $28.62 \pm 4.07$ & $28.16 \pm 4.05$ & $27.18 \pm 3.26$ & 0.56 & 0.05 & 0.13 \\
\hline BMI (kg/m2) & $21.51 \pm 3.02$ & $21.84 \pm 3.19$ & $21.34 \pm 2.94$ & $21.51 \pm 3.02$ & 0.39 & 0.59 & 0.74 \\
\hline Reoperation n.(\%) & $35(19.89 \%)$ & $11(26.19 \%)$ & $11(14.86 \%)$ & $13(21.67 \%)$ & 0.14 & 0.6 & 0.31 \\
\hline \multicolumn{8}{|l|}{ Endometriosis } \\
\hline Yes & $43 / 91(47.25 \%)$ & $2 / 6(33.33 \%)$ & $16 / 36(44.44 \%)$ & $25 / 49(51.02 \%)$ & 0.95 & 0.7 & 0.55 \\
\hline No & $48 / 91(52.75 \%)$ & $4 / 6(66.67 \%)$ & $20 / 36(55.56 \%)$ & $24 / 49(48.98 \%)$ & & & \\
\hline \multicolumn{8}{|l|}{ Infertility } \\
\hline Primary & $60 / 131(45.80 \%)$ & / & / & $60(100 \%)$ & / & / & / \\
\hline Secondary & 71/131 (54.20\%) & 27 (64.29\%) & $44(59.46 \%)$ & / & 0.608 & / & / \\
\hline \multicolumn{8}{|l|}{ Menstruation } \\
\hline Irregular & $17(9.66 \%)$ & $7(16.67 \%)$ & $5(6.76 \%)$ & $5(8.33 \%)$ & 0.17 & 0.33 & 0.99 \\
\hline Regular & $159(90.34 \%)$ & $35(83.33 \%)$ & $69(93.24 \%)$ & $55(91.67 \%)$ & & & \\
\hline \multicolumn{8}{|l|}{ Classification } \\
\hline Partial septate uterus & 114 (64.77\%) & $33(78.57 \%)$ & $49(66.22 \%)$ & $32(53.33 \%)$ & 0.16 & 0.01 & 0.13 \\
\hline Complete septate uterus & $62(35.23 \%)$ & $9(21.43 \%)$ & $25(33.78 \%)$ & $28(46.67 \%)$ & & & \\
\hline \multicolumn{8}{|l|}{ Operation } \\
\hline Hysteroscope & $85(48.30 \%)$ & $36(85.71 \%)$ & $38(51.35 \%)$ & $11(18.33 \%)$ & 0 & 0 & 0 \\
\hline Hysteroscopy+laparoscopy & $91(51.70 \%)$ & $6(14.29 \%)$ & $36(48.65 \%)$ & $49(81.67 \%)$ & & & \\
\hline \multicolumn{8}{|l|}{ Adjuvant therapy } \\
\hline IUD & $70 / 117(59.83 \%)$ & $15 / 31(48.39 \%)$ & $25 / 43(58.14 \%)$ & $30 / 43(69.77 \%)$ & 0.41 & 0.06 & 0.26 \\
\hline Balloon & $47 / 117(40.17 \%)$ & $16 / 31(51.61 \%)$ & $18 / 43(41.86 \%)$ & $13 / 43(30.23 \%)$ & & & \\
\hline
\end{tabular}

\section{Reproductive Outcomes}

The overall pregnancy outcome of the included cases is shown in Table 2: The preoperative pregnancy rate was $65.91 \%$, the postoperative rate was $77.27 \%$; the preoperative spontaneous abortion rate was $46.59 \%$, and the postoperative rate was $17.05 \%$; the preoperative live birth rate was only $7.95 \%$, the postoperative live birth rate reached $67.61 \%$. Although the preterm birth rate increased from $1.70 \%$ before surgery to $10.23 \%$, the preterm live birth rate also increased from $1.14-8.52 \%$. According to Table 3 , the pregnancy rate, spontaneous abortion rate, premature birth rate, and cesarean section rate of RSA patients (Group A) after hysteroscopic metroplasty were not significantly different from the other two groups, but the live birth rate and term birth rate were significantly lower.

Table 2

Comparison of reproductive outcome before and after hysteroscopic septoplasty

\begin{tabular}{|llllll|}
\hline $\mathrm{n}=176$ & Before septum resection & After septum resection & P value & RR & OR \\
\hline Pregnant & $116(65.91 \%)$ & $136(77.27 \%)$ & 0.02 & 1.17 & 1.76 \\
\hline Spontaneous abortion & $82(46.59 \%)$ & $30(17.05 \%)$ & 0.00 & 0.37 & 0.24 \\
\hline Live birth & $14(7.95 \%)$ & $119(67.61 \%)$ & 0.00 & 8.50 & 24.16 \\
\hline Term delivery & $13(7.39 \%)$ & $104(59.09 \%)$ & 0.00 & 8.00 & 18.11 \\
\hline Preterm birth & $3(1.70 \%)$ & $18(10.23 \%)$ & 0.00 & 6.00 & 6.57 \\
\hline Preterm live births & $2(1.14 \%)$ & $15(8.52 \%)$ & 0.00 & 7.50 & 8.11 \\
\hline
\end{tabular}


Table 3

Obstetric outcome after hysteroscopic septoplasty in three group

\begin{tabular}{|lllllll|}
\hline After septum resection & GroupA & GroupB & GroupC & Group Avs.B & $\begin{array}{l}\text { Group Avs.C } \\
\text { Group Bvs.C }\end{array}$ & $\begin{array}{l}\text { Group } \\
\text { P value }\end{array}$ \\
\hline Pregnant & $30(71.43 \%)$ & $61(82.43 \%)$ & $45(75.00 \%)$ & 0.17 & 0.69 & 0.29 \\
\hline Live birth & $21(50.00 \%)$ & $55(74.32 \%)$ & $43(71.67 \%)$ & 0.01 & 0.03 & 0.73 \\
\hline Abortions & $9(21.43 \%)$ & $13(17.57 \%)$ & $8(13.33 \%)$ & 0.61 & 0.28 & 0.50 \\
\hline Term delivery & $16(38.10 \%)$ & $52(70.27 \%)$ & $36(60.00 \%)$ & 0.00 & 0.03 & 0.21 \\
\hline Preterm births & $7(16.67 \%)$ & $3(4.05 \%)$ & $8(13.33 \%)$ & 0.05 & 0.64 & 0.10 \\
\hline Preterm live births & $5(11.90 \%)$ & $3(4.05 \%)$ & $7(11.67 \%)$ & 0.22 & 1.00 & 0.18 \\
\hline Cesarean section & $16 / 23(69.57 \%)$ & $45 / 55(81.82 \%)$ & $32 / 44(72.73 \%)$ & 0.23 & 0.79 & 0.28 \\
\hline
\end{tabular}

\section{Subgroup Analyses}

Table 4 categorizes the fertility status of the included cases before and after surgery according to factors such as age, septum size, endometriosis, surgical methods, and infertility types: the preoperative live birth rate of septate uterus patients younger than 30 years old was only $4.07 \%$ (5/123), which was significantly lower than that of patients older than $30(16.98 \%, 9 / 53, p=0.01)$. But after hysteroscopic uterine septum resection, the live birth rate of patients younger than 30 has a very significant boost, reaching $73.17 \%(90 / 123, p=0.02)$.

Table 4

Subgroup analysis

\begin{tabular}{|c|c|c|c|c|c|c|c|c|c|c|c|c|}
\hline & & Before septun & resecti & & & & & After septum & esectio & & & \\
\hline & $\mathrm{n}$. & Pregnancy & $\mathrm{P}$ & Life birth & $\mathrm{P}$ & Abortions & $\mathrm{P}$ & Pregnancy & $\mathrm{P}$ & Life birth & $\mathrm{P}$ & Abortions \\
\hline Age & & & 0.08 & & 0.01 & & 0.92 & & 0.05 & & 0.02 & \\
\hline$<30$ & 123 & $76(61.79 \%)$ & & $5(4.07 \%)$ & & $57(46.34 \%)$ & & $100(81.30 \%)$ & & $90(73.17 \%)$ & & $20(16.26 \%)$ \\
\hline$\geq 30$ & 53 & $40(75.47 \%)$ & & $9(16.98 \%)$ & & $25(47.17 \%)$ & & $36(67.92 \%)$ & & $29(54.72 \%)$ & & $10(18.87 \%)$ \\
\hline Classification & & & 0.02 & & 0.16 & & 0.06 & & 0.06 & & 0.09 & \\
\hline $\begin{array}{l}\text { Partial } \\
\text { septate }\end{array}$ & 114 & $82(71.93 \%)$ & & $12(10.53 \%)$ & & $59(51.75 \%)$ & & $83(72.81 \%)$ & & $72(63.16 \%)$ & & $20(17.54 \%)$ \\
\hline $\begin{array}{l}\text { Complete } \\
\text { septate }\end{array}$ & 62 & $34(54.84 \%)$ & & $2(3,23 \%)$ & & 23(37.10\%) & & $53(85.48 \%)$ & & $47(75.81 \%)$ & & $10(16.13 \%)$ \\
\hline Endometriosis & & & 0.44 & & 0.15 & & 0.49 & & 0.39 & & 0.33 & \\
\hline Yes & 43 & 18(41.86\%) & & $1(2.33 \%)$ & & $9(20.93 \%)$ & & $33(76.74 \%)$ & & $31(72.09 \%)$ & & $6(13.95 \%)$ \\
\hline No & 48 & $24(50.00 \%)$ & & $6(12.50 \%)$ & & $13(27.08 \%)$ & & $33(68.75 \%)$ & & $30(62.50 \%)$ & & $6(12.50 \%)$ \\
\hline Operation & & & 0.00 & & 0.89 & & 0.00 & & 0.12 & & 0.87 & \\
\hline $\mathrm{H}$ & 85 & $74(87.06 \%)$ & & $7(8.24 \%)$ & & $60(70.59 \%)$ & & $70(82.35 \%)$ & & $58(68.24 \%)$ & & $18(21.18 \%)$ \\
\hline $\mathrm{H}+\mathrm{L}$ & 91 & $42(46.15 \%)$ & & $7(7.69 \%)$ & & $22(24.18 \%)$ & & $66(72.53 \%)$ & & $61(67.03 \%)$ & & $12(13.19 \%)$ \\
\hline $\begin{array}{l}\text { Adjuvant } \\
\text { therapy }\end{array}$ & & & 0.10 & & 1.00 & & 0.06 & & 0.44 & & 0.11 & \\
\hline IUD & 70 & $40(57.14 \%)$ & & $4(5.71 \%)$ & & $28(40.00 \%)$ & & $59(84.29 \%)$ & & $53(75.71 \%)$ & & $15(21.43 \%)$ \\
\hline Balloon & 47 & $34(72.34 \%)$ & & $2(4.26 \%)$ & & $27(57.45 \%)$ & & $37(78.72 \%)$ & & $29(61.70 \%)$ & & $10(21.28 \%)$ \\
\hline Infertility & & & 0.00 & & 0.00 & & 0.00 & & 0.74 & & 0.24 & \\
\hline Primary & 60 & $0(0.00 \%)$ & & $0(0.00 \%)$ & & $0(0.00 \%)$ & & $45(75.00 \%)$ & & $43(71.67 \%)$ & & $8(13.33 \%)$ \\
\hline Secondary & 71 & $71(100.00 \%)$ & & 11(15.49\%) & & $51(71.83 \%)$ & & $55(77.46 \%)$ & & $44(61.97 \%)$ & & $16(22.54 \%)$ \\
\hline
\end{tabular}


Table 5

Case-control study for patients combined with primary infertility or RSA

\begin{tabular}{|c|c|c|c|}
\hline $\begin{array}{l}\text { Primary infertility } \\
n=60\end{array}$ & $\begin{array}{l}\text { Postoperative pregnancy group } \\
(n=45)\end{array}$ & $\begin{array}{l}\text { Postoperative infertility group } \\
(n=15)\end{array}$ & $P$ value \\
\hline Age $(y)$ & $26.96 \pm 3.31$ & $27.87 \pm 3.11$ & 0.35 \\
\hline BMI (kg/m2) & $21.69 \pm 3.12$ & $20.94 \pm 2.70$ & 0.41 \\
\hline Complete septate uterus & $24(53.33 \%)$ & $4(26.67 \%)$ & 0.07 \\
\hline Endometriosis & $19(42.22 \%)$ & $6(40.00 \%)$ & 0.88 \\
\hline Endometrial polyps & $19(42.22 \%)$ & $4(26.67 \%)$ & 0.28 \\
\hline Laparoscope & $37(82.22 \%)$ & $12(80.00 \%)$ & 1.00 \\
\hline Reoperation & $10(22.22 \%)$ & $3(20.00 \%)$ & 1.00 \\
\hline IUD & $23(51.11 \%)$ & $7(46.67 \%)$ & 0.77 \\
\hline Balloon & $11(24.44 \%)$ & $2(13.33 \%)$ & 0.59 \\
\hline $\begin{array}{l}\text { RSA } \\
\mathrm{n}=42\end{array}$ & $\begin{array}{l}\text { Postoperative live birth group } \\
(n=21)\end{array}$ & $\begin{array}{l}\text { Postoperative Non-live birth group } \\
(\mathrm{n}=21)\end{array}$ & $P$ value \\
\hline Pregnancy (n) & $2.57 \pm 0.87$ & $3.29 \pm 1.27$ & 0.04 \\
\hline Abortions (n) & $2.33 \pm 0.66$ & $2.71 \pm 0.90$ & 0.13 \\
\hline Age $(y)$ & $28.19 \pm 3.33$ & $29.05 \pm 4.74$ & 0.50 \\
\hline BMI (kg/m2) & $21.32 \pm 2.23$ & $22.35 \pm 3.91$ & 0.30 \\
\hline Complete septate uterus & $5(23.81 \%)$ & $4(19.05 \%)$ & 1.00 \\
\hline Endometriosis & $2(9.52 \%)$ & $0(0.00 \%)$ & 0.47 \\
\hline Endometrial polyps & $3(14.29 \%)$ & 3 (14.29\%) & 1.00 \\
\hline Laparoscope & $4(19.05 \%)$ & $2(9.52 \%)$ & 0.66 \\
\hline Reoperation & 7 (33.33\%) & $4(19.05 \%)$ & 0.29 \\
\hline IUD & $8(38.10 \%)$ & $7(33.33 \%)$ & 0.75 \\
\hline Balloon & $7(33.33 \%)$ & $9(42.86 \%)$ & 0.53 \\
\hline
\end{tabular}

For patients with complete uterine septum, the preoperative pregnancy rate was $54.84 \%(34 / 62)$, which was significantly lower than that of patients with partial uterine septum $(71.93 \%, \mathrm{P}=0.02)$. After surgery, the pregnancy rate of patients with complete uterine septum increased to $85.48 \%(53 / 63)$, however, there were no statistical differences compared to the patients with partial uterine septum.

Among the included cases, 85 cases (48.30\%) underwent hysteroscopic uterine septum resection, 91 cases (51.70\%) underwent hysteroscopy combined with laparoscopy. For patients who underwent only hysteroscopic surgery, the preoperative pregnancy rate and miscarriage rate were both significantly higher than the other group. However there was no statistical difference was observed in the pregnancy rate and miscarriage rate between the two groups after the operation.

\section{Case-control Study}

In the 60 patients with primary infertility, 15 were still unsuccessful conceived during the follow-up after the operation, the remaining 45 were successful pregnancy; Early miscarriages occurred in 8 women after the operation, and there were 43 live births, including 7 preterm births and 36 full-term births; The cesarean section rate was $76.74 \%$ (33/43). Univariate analysis found that there were no significant differences in age, BMI, septum size, surgical methods, endometriosis, and endometrial polyps between the postoperative pregnancy group and the postoperative infertility group.

Among 42 patients with recurrent miscarriage, the postoperative live birth rate was $50 \%$ (21/42), including 5 preterm births and 16 full-term births, and the cesarean section rate was $76.19 \%(16 / 21)$. Early miscarriages occurred in 9 women after surgery. Univariate study found that the number of pre-operative pregnancies in the RSA live birth group was significantly less than that in the RSA non-live birth group $(p=0.04)$. The remaining factors like number of miscarriages, age, BMI, septum size, surgical methods, and endometriosis or endometrial polyps showed no significant differences between the two groups.

\section{Discussion}

Since 1970, hysteroscopic uterine septum resection has become the first-line therapy for septate uterus ${ }^{[21]}$ and has been widely performed in many countries $^{[22]}$. Compared with traditional laparotomy, hysteroscope offers benefits such as small trauma, quick recovery, and shorter postoperative 
contraceptive time ${ }^{[23]}$; its main complications include intraoperative bleeding, uterine perforation, water poisoning, intrauterine adhesions and increase the risk of uterine rupture when pregnancy again ${ }^{[19]}$. It is necessary to strictly assesse the risk and benefit of surgery ${ }^{[24]}$. At present, there is still a controversy for the surgical indications for septate uterus, considering there are probably no obvious symptoms for such patients, which was incidentally detected at cesarean section or physical examination. Often, this disease is mainly related to the adverse pregnancy outcomes, however, some patients with septate uterus can also experience a normal pregnancy and spontaneous delivery ${ }^{[19]}$.

In my country, surgical treatment can be performed for patients with uterine septum who have fertility requirements and have a history of infertility and poor maternal outcome, according to the Chinese expert consensus on the diagnosis and treatment of female genital tract anomalies (2015). However, foreign literature reported that there is no sufficient evidence to prove that the uterine septum can cause infertility ${ }^{[3]}$. In the present study, primary infertility accounted for $34.09 \%$ (60/176), of which 49 patients performed hysteroscopic + laparoscopic surgery. Table1 shows that the proportion of patients with primary infertility to perform laparoscopic surgery was significantly higher than patients with fertility histories; this is because laparoscopic surgery can simultaneously check the patency of the fallopian tubes, pelvic endometriosis, adnexal masses, etc ${ }^{[25]}$. Although the pregnancy rate of these 49 patients was as high as $75.51 \%(37 / 49)$ and the live birth rate was $71.43 \%$ (35/49) after surgery, it is difficult to determine whether the improvement in pregnancy outcome is caused by the removal of the mediastinum, due to the impact of confounding factors. 11 patients with primary infertility underwent hysteroscopic surgery only. After the operation, 8 patients were successfully conceived and delivered (pregnancy and live birth rate $72.73 \%$ ), including 2 premature births and 6 fullterm births. It is suggested that uterine septum resection may still have some positive significance for patients with primary infertility, which is consistent with the findings of Panagiotis Bakas et al. ${ }^{[26]}$. Similarly, a recent retrospective cohort study found that mediastinal resection in patients with primary infertility can reduce the spontaneous abortion rate after IVF/ICSI ${ }^{[27]}$.

Septate uterus with a history of recurrent miscarriage is a recognized surgical indication ${ }^{[28]}$, and even some studies have pointed out that surgical treatment is only recommended for such patients ${ }^{[29]}$. A prospective study by Li-Hong Pang et al. ${ }^{[30]}$ confirmed that septum resection can significantly increase the pregnancy rate and term delivery rate of RSA patients, and reduce the rate of miscarriage and preterm birth, compared with the control group. In this study, the live birth rate of 42 RSA patients increased from 7.14-50\% after surgery, but it was still significantly lower than non-RSA patients (73.13\%). Since the etiology of RSA is multifactorial and has not been clearly elucidated yet, and related to the factors like uterus anomalies, chromosomal abnormalities, endocrine, infection, thrombophilia, immunity, etc. ${ }^{[31]}$ suggesting that the influence of these factors should be excluded before uterine septum resection in patients with RSA. The univariate analysis found that the live birth rate in RSA patients might relate to the number of preoperative pregnancy, but this result needs to be verified by expanding the sample size.

The traditional belief is that surgical removal of the uterine septum can improve reproductive outcome by recovering the normal anatomical structure of the uterus. This is mainly based on a series of retrospective cohort studies published in the early years ${ }^{[32]}$. However, most of these studies with a before-and-after design may exaggerate the surgery effect, therefore this view is currently questioned. Opponents argue that hysteroscopic metroplasty could increased the risk of obstetric complications ${ }^{[33]}$, and the risks of surgery outweigh the benefits. Among the 176 cases included in the present study, severe obstetric complications were experienced in only 1 patient (uterine rupture) and the cesarean section rate was as high as $76.23 \%(93 / 122)$.

A Cochrane review ${ }^{[34]}$ published in 2017 summarized 9 previously published literature, of which 3 studies showed that the pregnancy rate after uterine septum resection was significantly higher than expecting treatment group, while 6 studies found that there was no significant difference in pregnancy outcomes between the two groups. In 2020, an international multicentre cohort study ${ }^{[14]}$ included 257 patients with septate uterus, 151 patients underwent septum resection and 106 patients received expectant treatment. The results showed that the reproductive outcomes between the two groups have no significant difference. However, retrospective cohort study design clustered by the severity of the disease and reproductive history may weaken the effect of surgical treatment to some degree. Therefore, the same research team conducted another multicenter randomized controlled study with a sample size of 80 cases ${ }^{[13]}$ and also obtained the same conclusion. But due to the limitation of sample size, no further studies has been conducted on patients with different types of infertility or combined recurrent miscarriages. Regrettably, another randomized controlled study in the United Kingdom has been suspended due to difficult patient recruitment (ISRCTN28960271). It is hoped that more well-designed, large-sample, multicenter studies will be conducted in the future to provide higherquality evidence.

\section{Conclusions}

Although this retrospective study made the bias hardly be avoided and suffered from a high rate of lost follow-up, the overall pregnancy rate and live birth rate increase and the spontaneous abortion rate decreases after surgical removal of the uterine septum, according to the existing data. After septum resection, the live birth rate and term delivery rate of RSA patients were significantly lower than those of other two groups, but the pregnancy rate, spontaneous abortion rate, premature birth rate, and cesarean section rate were not significantly different from other patients. Women with complete uterine septum have a more significant increase in postoperative pregnancy rates. For patients had combined primary infertility, hysteroscopy combined with laparoscopy is recommended, which can explore the fallopian tube and pelvic cavity at the same time helping to increase the pregnancy rate.

\section{Declarations}

Funding: The authors declare that no funds, grants, or other support were received during the preparation of this manuscript.

Conflicts of Interest: The authors declare no conflict of interest.

Competing Interests: The authors have no relevant financial or non-financial interests to disclose. 
Ethics approval: This is an observational study. The Medical Ethics Committee of West China Second Hospital has confirmed that no ethical approval is required.

Informed Consent: Informed consent was obtained from all individual participants included in the study.

\section{Author Contribution}

Zhu Lan: Formal analysis, Visualization, Writing - Original Draft

Run He: Software, Resources, Investigation (collect the medical data)

Shanshan Zhou and Guangji Xia: Investigation (telephone follow-up)

Ying Long: Data Curation

Mingrong Xi: Validation

Jing Fu: Methodology

Yunwei Ouyang: Conceptualization, Supervision, Review and Editing

\section{References}

1. Saridogan E, Salman M, Direk LS, Alchami A (2021) Reproductive Performance Following Hysteroscopic Surgery for Uterine Septum: Results from a Single Surgeon Data.J Clin Med. 10(1)

2. Bhagavath B, Ellie G, Griffiths KM et al (2017) Uterine Malformations: An Update of Diagnosis, Management, and Outcomes. Obstet Gynecol Surv 72(6):377-392

3. Uterine septum (2016) a guideline. Fertil Steril 106(3):530-540

4. Homer HA, Li TC, Cooke ID (2000) The septate uterus: a review of management and reproductive outcome. Fertil Steril 73(1):1-14

5. Grimbizis GF, Camus M, Tarlatzis BC, Bontis JN, Devroey P (2001) Clinical implications of uterine malformations and hysteroscopic treatment results. Hum Reprod Update 7(2):161-174

6. Raga F, Casañ EM, Bonilla-Musoles F (2009) Expression of vascular endothelial growth factor receptors in the endometrium of septate uterus. Fertil Steril 92(3):1085-1090

7. Fayez JA (1986) Comparison between abdominal and hysteroscopic metroplasty. Obstet Gynecol 68(3):399-403

8. Fedele L, Bianchi S, Marchini M, Franchi D, Tozzi L, Dorta M (1996) Ultrastructural aspects of endometrium in infertile women with septate uterus. Fertil Steril 65(4):750-752

9. Sparac V, Kupesic S, llijas M, Zodan T, Kurjak A (2001) Histologic architecture and vascularization of hysteroscopically excised intrauterine septa. J Am Assoc Gynecol Laparosc 8(1):111-116

10. Gundabattula SR, Joseph E, Marakani LR, Dasari S, Nirmalan PK (2014) Reproductive outcomes after resection of intrauterine septum. J Obstet Gynaecol 34(3):235-237

11. Freud A, Harlev A, Weintraub AY, Ohana E, Sheiner E (2015) Reproductive outcomes following uterine septum resection. J Matern Fetal Neonatal Med 28(18):2141-2144

12. Tonguc EA, Var T, Batioglu S (2011) Hysteroscopic metroplasty in patients with a uterine septum and otherwise unexplained infertility. Int J Gynaecol Obstet 113(2):128-130

13. Rikken J, Kowalik CR, Emanuel MH et al (2021) Septum resection versus expectant management in women with a septate uterus: an international multicentre open-label randomized controlled trial. Hum Reprod 36(5):1260-1267

14. Rikken J, Verhorstert K, Emanuel MH et al (2020) Septum resection in women with a septate uterus: a cohort study. Hum Reprod 35(7):1578-1588

15. Vercellini P, Chiaffarino F, Parazzini F (2021) 'It's all too much't: the shadow of overtreatment looms over hysteroscopic metroplasty for septate uterus. Hum Reprod 36(5):1166-1170

16. Sugi MD, Penna R, Jha P et al (2021) Müllerian Duct Anomalies: Role in Fertility and Pregnancy. Radiographics 41(6):1857-1875

17. Practice Committee of the American Society for Reproductive Medicine (2020) Electronic address: asrm@asrm.org. Definitions of infertility and recurrent pregnancy loss: a committee opinion. Fertil Steril 113(3):533-535

18. Bender Atik R, Christiansen OB, Elson J et al (2018) ESHRE guideline: recurrent pregnancy loss. Hum Reprod Open 2018(2):hoy004

19. Valle RF, Ekpo GE (2013) Hysteroscopic metroplasty for the septate uterus: review and meta-analysis. J Minim Invasive Gynecol 20(1):22-42

20. Grimbizis GF, Gordts S, Di Spiezio Sardo A et al (2013) The ESHRE-ESGE consensus on the classification of female genital tract congenital anomalies. Gynecol Surg 10(3):199-212

21. Edström K, Fernström I (1970) The diagnostic possibilities of a modified hysteroscopic technique. Acta Obstet Gynecol Scand 49(4):327-330

22. Paradisi R, Barzanti R, Fabbri R (2014) The techniques and outcomes of hysteroscopic metroplasty. Curr Opin Obstet Gynecol 26(4):295-301

23. Yin X, Cheng J, Ansari SH et al (2018) Hysteroscopic tissue removal systems for the treatment of intrauterine pathology: a systematic review and metaanalysis. Facts Views Vis Obgyn 10(4):207-213 
24. Checa MA, Bellver J, Bosch E et al (2018) Hysteroscopic septum resection and reproductive medicine: A SWOT analysis. Reprod Biomed Online 37(6):709-715

25. Zhang E, Zhang Y, Fang L, Li Q, Gu J (2014) Combined hysterolaparoscopy for the diagnosis of female infertility: a retrospective study of 132 patients in china. Mater Sociomed 26(3):156-157

26. Bakas P, Gregoriou O, Hassiakos D, Liapis A, Creatsas M, Konidaris S (2012) Hysteroscopic resection of uterine septum and reproductive outcome in women with unexplained infertility. Gynecol Obstet Invest 73(4):321-325

27. Chen HX, Lv SG, Zhang YN et al (2021) Effect of hysteroscopic septum resection on subsequent in vitro fertilization-intracytoplasmic sperm injection outcomes in cases of primary infertility. J Gynecol Obstet Hum Reprod 50(9):102149

28. Carrera M, Pérez Millan F, Alcázar JL et al (2021) Effect of Hysteroscopic Metroplasty on Reproductive Outcomes in Women with Septate Uterus: Systematic Review and Meta-Analysis.J Minim Invasive Gynecol.

29. Akhtar MA, Saravelos SH, Li TC, Jayaprakasan K (2020) Reproductive Implications and Management of Congenital Uterine Anomalies: Scientific Impact Paper No. 62 November 2019. BJOG 127(5):e1-e13

30. Pang LH, Li MJ, Li M, Xu H, Wei ZL (2011) Not every subseptate uterus requires surgical correction to reduce poor reproductive outcome. Int J Gynaecol Obstet 115(3):260-263

31. Dimitriadis E, Menkhorst E, Saito S, Kutteh WH, Brosens JJ (2020) Recurrent pregnancy loss. Nat Rev Dis Primers 6(1):98

32. Fox NS, Connolly CT, Hill MB, Klahr RA, Zafman KB, Rebarber A (2019) Pregnancy outcomes in viable pregnancies with a septate uterus compared with viable pregnancies after hysteroscopic uterine septum resection. Am J Obstet Gynecol MFM 1(2):136-143

33. Agostini A, De Guibert F, Salari K, Crochet P, Bretelle F, Gamerre M (2009) Adverse obstetric outcomes at term after hysteroscopic metroplasty. J Minim Invasive Gynecol 16(4):454-457

34. Rikken JF, Kowalik CR, Emanuel MH et al (2017) Septum resection for women of reproductive age with a septate uterus. Cochrane Database Syst Rev 1(1):CD008576

\section{Figures}

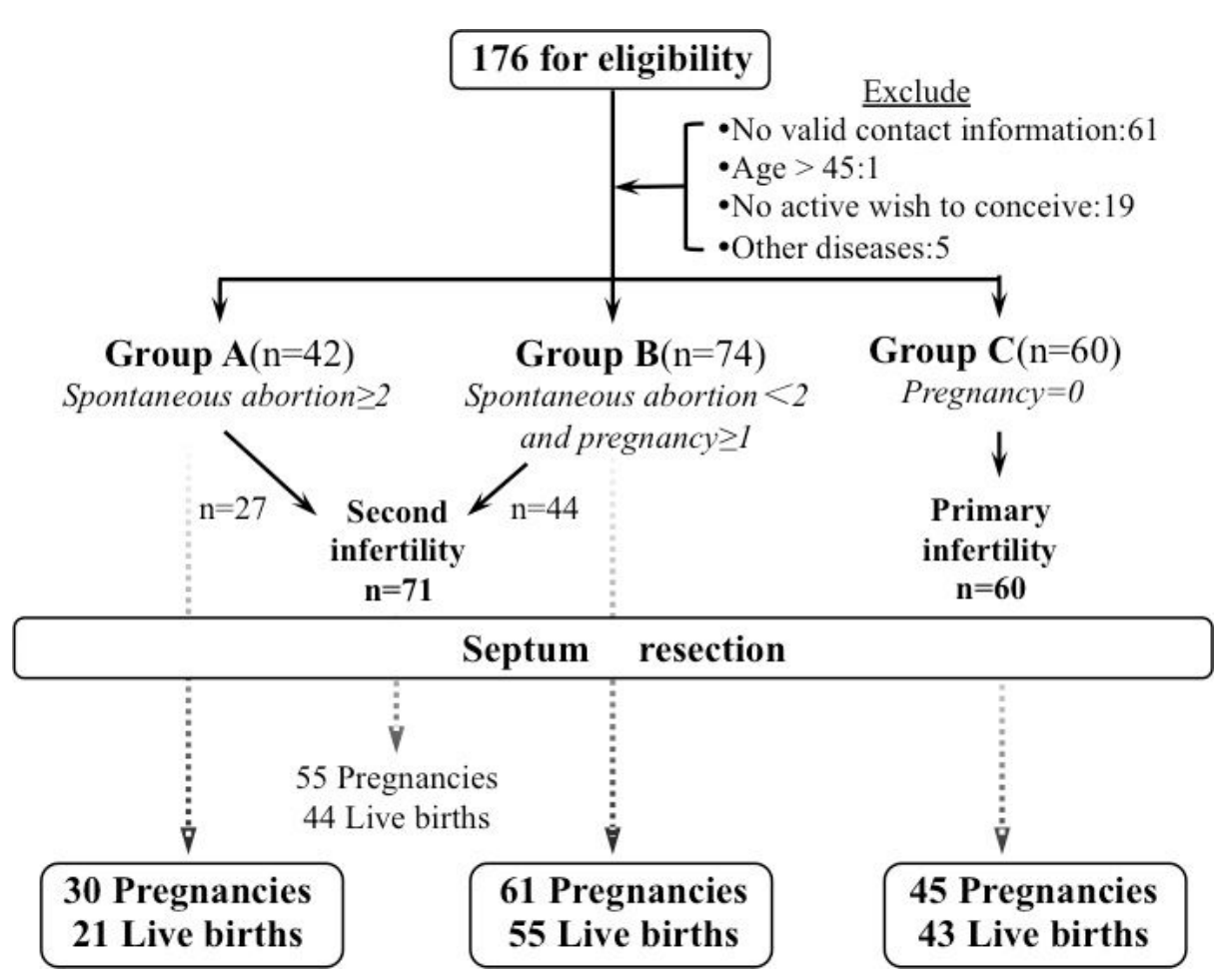

Figure 1

Flow diagram of reproductive outcomes. 